Assist Reprod Genet. 2014;31(5):549-554. doi:10.1007/s10815-014-0215-2

5. ji G, Gu A, Wang $Y$, et al. Genetic variants in antioxidant genes are associated with sperm DNA damage and risk of male infertility in a Chinese population. Free Radic Biol Med. 2011;52:775-780. doi:10.1016/j.freeradbiomed.2011.11.032

6. Bousnane NEH, May S, Yahia M, Abu Alhaija AA. Association of CAT-262C/T with the concentration of catalase in seminal plasma and the risk for male infertility in Algeria. Syst Biol Reprod Med. 2017;63(5):303-310. doi:10.1080/19396368.2017.1318187

7. García Rodríguez $A$, de la Casa M, Johnston S, Gosálvez J, Roy R. Association of polymorphisms in genes coding for antioxidant enzymes and human male infertility. Ann Hum Genet. 2019;83(1):63-72. doi:10.1111/ahg.12286

8. Hsieh $\mathbf{Y - Y}$, Sun $\mathbf{Y}-\mathrm{L}$, Chang $C-C$, Lee $\mathbf{Y}-\mathbf{S}$, Tsai H-D, Lin C-S. Superoxide dismutase activities of spermatozoa and seminal plasma are not correlated with male infertility. J Clin Lab Anal. 2002;16(3):127-131. doi:10.1002/jcla.10029

9. Savikina KG, Abd Ali AH, Shkurat TP, Lomteva SV, Karantysh GV. Association of CAT C262T (rs1001179) polymorphism with male infertility: Meta-analysis. Meta Gene. Published online September 10, 2021:100974. doi:10.1016/j.mgene.2021.100974

\title{
NGHIÊN CỨU TỶ LÊ POLYP ĐAI TRỰC TRÀNG UNG THƯ THEO KÍCH THƯỚC
}

\section{TÓM TẮT}

Mục tiêu "Nghiên cứu mối liên quan giữa tuổi, hình ảnh nối soi với kích thước polyp đai trức tràng ung thư". Đối tượng và phương pháp nghiên cứu: Nghiên cứu tiến cứu, mô tả, cắt ngang. Trên 284 bệnh nhân với 362 polyps bao gồm 13 polyp ung thư tại Bênh viện Bạch mai, thời gian từ 8/2020 đến 8/202i. Kết quả: Tuổi trung bình của bệnh nhân polyp ung thư là 64 (nhỏ nhất 32, lớn nhất 85 tuổi). Trong nghiên cứu này kích thước polyps $<10 \mathrm{~mm}$ không ghi nhâanpolyp ung thư. Kích thước trung bình polyp ung thư là 24,38 $\pm 9,87 \mathrm{~mm}$ (nhỏ nhất $10 \mathrm{~mm}$, lớn nhất $50 \mathrm{~mm}$ ). Polyps ung thư chủ yếu ở đại tràng sigma và trực tràng: $46,2 \%$ và $38,5 \%$. Tỷ lể polyps ung thư theo kích thước: $10-19 \mathrm{~mm} 3,96 \%, 20-29 \mathrm{~mm}$ $11,42 \%$ và $\geq 30 \mathrm{~mm} 25 \%$. $92,3 \%$ polyps ungthư ở bệnh nhân $\geq 40$ tuổi. Kết luận: Polyp đại trực tràng được xem là tổn thương tiền ung thư', nên nội soi đại trưc tràng tầm soát ung thư ở người $\geq 40$ tuổi, kể cả người không có dấu hiệu chỉ điểm. Nên cắt polyp đại trực tràng, đặc biệt những polyps có kích thước $\geq$ $10 \mathrm{~mm}$.

Tư khóa: Nội soi đại tràng, polyp đại trực tràng.

\section{SUMMARY}

\section{STUDY THE RATIO OF COLORECTAL CANCEROUS POLYPS ACCORDING TO THE SIZE OF POLYP}

Aims "Study on the relationship of age,

\footnotetext{
${ }^{1}$ Trung tâm Tiêu hóa - Gan mật, Bệnh viện Bạch mai, ${ }^{2}$ Trướng Đại học Y Hà nọi

${ }^{3}$ Bênh viên Đa khoa Hưng Hà, Hưng yên

Chịu trách nhiệm chính: Nguyễn Trường Sơn

Email: Nguyentruongsonbm@yahoo.com

Ngày nhận bài: 3.8.2021

Ngày phản biên khoa hoc: 28.9.2021

Ngày duyệt bài: 5.10 .2021
}

Nguyễn Trường Sơnn', Hoàng Mai Hương², Đỗ Khắc Trường ${ }^{3}$, Đinh Thanh Tuấn ${ }^{2}$

endoscopic image with cancerous colorectal polyps according to the size of polyps". Research Patients and methods: A prospective, descriptive, crosssectional study. Enroll 284 patients with 362 polyps including 13 cancerous polyps at Bach Mai Hospital, from 8/2020 to 8/2021. Results: The average age of patients with cancerous polyps was 64 (the youngest 32 , the oldest 85 years old). In this study, polyp size $<10 \mathrm{~mm}$ without cancerous polyps. Cancerous polyps mainly in the sigmoid colon and rectum: $46.2 \%$ and $38.5 \%$. The average size of cancerous polyps is 24.38 $\pm 9.87 \mathrm{~mm}$ ( $10 \mathrm{~mm}$ minimum, $50 \mathrm{~mm}$ maximum). The percentage of cancerous polyps according to size: 10 $19 \mathrm{~mm} 3.96 \%, 20-29 \mathrm{~mm} 11.42 \%$, and $\geq 30 \mathrm{~mm} 25 \%$. $92.3 \%$ cancerous polyps in patients $\geq 40$ years old Conclusions: Colorectal polyps are considered premalignant lesions, so colonoscopy to screen for cancer in people $\geq 40$ years old, including those asymptomatic. Colorectal polyps should be removed, especially polyps $\geq 10 \mathrm{~mm}$.

Keywords: Colonoscopy, colorectal cancerous polyps.

\section{I. ĐẶT VẤN ĐỀ}

Polyp đại trực trànglà phần nhô ra bất thường của niêm mạc vào trong lòng đại trực tràng ${ }^{1}$, một bệnh lý phổ biến ở Việt Nam cũng như trên thế giới $i^{2,3}$. Hầu hết các ung thư đại trực tràng được phát triển từ polyp tuyến của đại trực tràng, từ lúc nhỏ đến loạn sản và cuối cùng tiến triển thành ung thư. Do đó, polyp đại trực được xem là tiền ung thư, đặc biệt với những polyp có kích thước lớn. Nội soi đại tràng cùng mô bệnh học của polyp cho chúng ta biết được vị trí, kích thước và bản chất của polyp, qua đó nhà lâm sàng đưa ra quyết định điêu trị và tiên lượng một cách chính xác hơn. Vì vậy, chúng tôi nghiên cứu đề tài với mục tiêu: Nghiên cứu mối liên 
quan giữa tuôil, hinh ảnh nọi soi với kích thước polyp đại trức tràng ung thur.

II. ĐỐI TƯợNG VÀ PHƯƠNG PHÁP NGHIÊN CỨU

2.1. Địa điểm nghiên cứu: Bệnh viện Bạch mai. Thời gian nghiên cứu: 8/2020 đến $8 / 2021$.

2.2. Đối tượng nghiên cứu: Đối tượng nghiên cứu được chọn vào nghiên cứu thỏa mãn các điều kiện sau:

- Bệnh nhân được nội soi đại trực tràng

- Có kết quả mô bệnh học sau cắt polyp qua nội soi hoặc phẫu thuật

- Đồng ý tham gia nghiên cứu

- Tiểu cầu > 100.000 G/l, đông máu cơ bản bình thường.

2.3 Cỡ mẫu: Lấy mẫu thuận tiện 284 bệnh nhân, 362 polyp trong đó có 13 polyp ung thư đủ tiêu chuẩn lấy vào nghiên cứu.

2.4 Thiết kế nghiên cứu: Nghiên cứu tiến cứu, mô tả, cắt ngang.

2.5 Phương pháp nghiên cứu: Bệnh nhân được khám lâm sàng, nội soi đại tràng theo qui trình do Bộ y tế ban hành bằng hệ thống máy nội soi Fujinon 600 (Nhật bản), polyp được làm mô bệnh học sau cắt polyp qua nội soi hoặc phẫu thuật, phân loại mô bệnh học của polyp theo tiêu chuẩn WHO 2020. Số liệu được thu thập và xử lý bằng phần mềm SPSS 16.0, tính tỷ lệ phần trăm, giá trị trung bình, độ lệch chuẩn, $p$ có ý nghĩa thống kê khi $\mathrm{p}<0,05$.

\section{KẾT QUẢ NGHIÊN CỨU}

Trong thời gian nghiên cứu từ $8 / 2020$ đến 8/2021, 284 bệnh nhân với 362 polyp trong đó có 13 polyp ung thư.

3.1 Đặc điểm về giới và tuổi của nhóm nghiên cứu: Tuổi trung bình của nhóm nghiên cứu 55,32 $\pm 14,62$, nhỏ nhất 13 và cao nhất 89 tuổi, phần lớn polyps gặp trên 40 tuổi với tỷ lệ 85,9\%, tỷ lệ nam/nữ 1,2/1.

3.2 Mối liên quan giữa tuổi và kích thước polyp ung thư

Bảng 1: Môi liên quan giữa tuổi và kích thước polyp ung thư

\begin{tabular}{|c|c|c|c|c|c|c|c|c|}
\hline \multirow{2}{*}{$\begin{array}{l}\text { Kích thước }(\mathrm{mm}) \\
\text { Nhóm tuổi }\end{array}$} & \multicolumn{2}{|c|}{$10-19$} & \multicolumn{2}{|c|}{$20-29$} & \multicolumn{2}{|c|}{$\geq \mathbf{3 0}$} & \multicolumn{2}{|c|}{ Tổng } \\
\hline & $\mathbf{n}$ & $\%$ & $\mathbf{n}$ & $\%$ & $\mathbf{n}$ & $\%$ & $\mathbf{n}$ & $\%$ \\
\hline$<20$ & 0 & 0 & 0 & 0 & 0 & 0 & 0 & 0 \\
\hline $20-39$ & 0 & 0 & 0 & 0 & 1 & 20 & 1 & 7,7 \\
\hline $40-59$ & 1 & 25 & 1 & 25 & 1 & 20 & 3 & 23,1 \\
\hline$\geq 60$ & 3 & 75 & 3 & 75 & 3 & 60 & 9 & 69,2 \\
\hline Tống & 4 & 100 & 4 & 100 & 5 & 100 & $\mathbf{1}$ & 100 \\
\hline $\mathrm{p}$ & & & & & & & & \\
\hline Trung vị (max - min) & & & & 64( & 85) & & & \\
\hline
\end{tabular}

Nhận xét: Bệnh nhân có tuối từ 40 trở lên có tỷ lệ polyp ung thư92,3\%. Có 1 bệnh nhân 32 tuổi có polyp $\geq 30 \mathrm{~mm}$ chiếm tỷ lệ $7,7 \%$.

Polyp ung thư có kích thước nhỏ nhất $10 \mathrm{~mm}$, lớn nhất 50mm, trung bình 24,38 $\pm 9,87 \mathrm{~mm}$. Tuổi trung bình của bệnh nhân có polyp ung thư là 64, bệnh nhân nhỏ tuổi nhất 32, lớn tuổi nhất 85 tuổi.

3.3 Mối liên quan giữa giới tính và kích thước polyp ung thư

Bảng 2: Mối liên quan giữa giới tính và kích thước polyp ung thư

\begin{tabular}{|c|c|c|c|c|c|c|}
\hline \multirow{2}{*}{ Kích thước polyp } & \multicolumn{2}{|c|}{ Nam tính } & \multicolumn{2}{c|}{ Nũ̃ } & \multicolumn{2}{c|}{ Tống } \\
\cline { 2 - 7 } & $\mathbf{n}$ & $\mathbf{\%}$ & $\mathbf{n}$ & $\mathbf{\%}$ & $\mathbf{n}$ & $\mathbf{\%}$ \\
\hline $10-19 \mathrm{~mm}$ & 1 & 25 & 3 & 75 & 4 & 100 \\
\hline $20-29 \mathrm{~mm}$ & 1 & 25 & 3 & 75 & 4 & 100 \\
\hline$\geq 30 \mathrm{~mm}$ & 3 & 60 & 2 & 40 & 5 & 100 \\
\hline Tống & 5 & 38,5 & 8 & 61,5 & 13 & 100 \\
\hline $\mathbf{p}$ & \multicolumn{3}{|c|}{$\mathbf{0 , 0 5}$} \\
\hline
\end{tabular}

Nhận xét: Tỷ lệ nữ nhiều hơn nam, sự khác biệt có ý nghĩa thống kê giữa polyp ung thư và giới tính với $p<0,05$.

3.4 Đặc điểm mô bệnh học của polyp đại trực tràng

Bảng 3: Đặc điểm mô bệnh học của polyp dại trức tràng

\begin{tabular}{|c|c|c|}
\hline Loại mô bệnh học & $\begin{array}{c}\text { Số polyp } \\
\text { (n) }\end{array}$ & $\begin{array}{c}\text { Tỉ lệ } \\
(\mathbf{\%})\end{array}$ \\
\hline Polyp tăng sản & 58 & 16,0 \\
\hline Polyp Juvenile & 10 & 2,8 \\
\hline
\end{tabular}

\begin{tabular}{|c|c|c|}
\hline Polyp Peutz - Jeghers & 1 & 0,3 \\
\hline Polyp viêm & 5 & 1,4 \\
\hline Polyp Hamartoma & 3 & 0,8 \\
\hline U tuyến & 267 & 73,8 \\
\hline U tuyến răng cưa & 5 & 1,4 \\
\hline Ung thư biếu mô tuyến & 13 & 3.6 \\
\hline Tống & $\mathbf{3 6 2}$ & $\mathbf{1 0 0}$ \\
\hline
\end{tabular}


Nhận xét: Polyp tuyến chiếm tỷ lệ cao nhất $73,8 \%$, ung thư biểu mô tuyến 3,6\%.

3.5 Mối liên quan giữa mô bệnh học và kích thước polyp ung thư

Bảng 4: Mối liên quan giữa mô bệnh học và kích thước polyp ung thur

\begin{tabular}{|c|c|c|c|}
\hline $\begin{array}{c}\text { Kích } \\
\text { thước } \\
\text { polyp } \\
(\mathbf{m m})\end{array}$ & $\begin{array}{c}\text { Polyp ung thư'/ } \\
\text { polyp khảo sát } \\
\text { theo kích thước } \\
\text { (\%) }\end{array}$ & $\begin{array}{c}\text { Tỉ lệ } \\
\text { ung } \\
\text { thứ } \\
(\%)\end{array}$ & $\mathrm{p}$ \\
\hline
\end{tabular}

\begin{tabular}{|c|c|c|c|}
\hline$\leq 5$ & $0 / 87$ & 0,00 & \\
\hline $6-9$ & $0 / 119$ & 0,00 & \\
\cline { 1 - 3 } $0-19$ & $4 / 101$ & 3,96 & $<0,05$ \\
\hline $20-29$ & $4 / 35$ & 11,42 & \\
\hline$\geq 30$ & $5 / 20$ & 25,0 & \\
\hline Tống & $\mathbf{1 3 / 3 6 2}$ & $\mathbf{3 , 5 9}$ & \\
\hline
\end{tabular}

Nhânn xét: Kích thước polyp càng lớn thì tỷ lệ ung thư càng cao: $\geq 30 \mathrm{~mm}$ tỷ lệ ung thư $25 \%$,

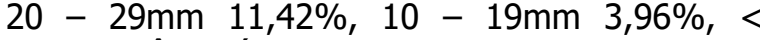
$10 \mathrm{~mm}$ không có polyp ung thư'.

3.6 Vị trí polyp theo kích thước trên nội soi

Bảng 5: Môi liên quan vị trí polyp và polyp ung thư theo kích thước

\begin{tabular}{|c|c|c|c|c|c|c|c|c|}
\hline \multirow{2}{*}{$\begin{array}{l}\text { Kích thước }(\mathrm{mm}) \\
\text { Vị trí polyp }\end{array}$} & \multicolumn{2}{|c|}{$10-19$} & \multicolumn{2}{|c|}{$20-29$} & \multicolumn{2}{|c|}{$\geq \mathbf{3 0}$} & \multicolumn{2}{|c|}{ Tống } \\
\hline & $\mathbf{n}$ & $\%$ & $\mathbf{n}$ & $\%$ & $\mathbf{n}$ & $\%$ & $\mathbf{n}$ & $\%$ \\
\hline Manh tràng & 0 & 0 & 0 & 0 & 1 & 20 & 1 & 7,7 \\
\hline ĐT lên & 1 & 25 & 0 & 0 & 0 & 0 & 1 & 7,7 \\
\hline ĐT ngang & 0 & 0 & 0 & 0 & 0 & 0 & 0 & 0 \\
\hline ĐT xuống & 0 & 0 & 0 & 0 & 0 & 0 & 0 & 0 \\
\hline ĐT sigma & 2 & 50 & 1 & 25 & 3 & 60 & 6 & 46,2 \\
\hline Trực tràng & 1 & 25 & 3 & 75 & 1 & 20 & 5 & 38,5 \\
\hline Tống & 4 & 100 & 4 & 100 & 5 & 100 & 13 & 100 \\
\hline $\mathbf{p}$ & & & & & & & & \\
\hline
\end{tabular}

Nhận xét: ĐT - đại tràng. Polyp ung thư ở đại tràng sigma 46,2\%, trực tràng 38,5\% là những vị trí polyp bị ung thư nhiều nhất.

3.7 Hình dang polyp ung thư theo kích thước

Bảng 6: Hình dạng polyp ung thư theo kích thước

\begin{tabular}{|c|c|c|c|c|c|c|c|c|}
\hline \multirow{2}{*}{$\begin{array}{l}\text { Kích thước }(\mathrm{mm}) \\
\text { Hình dạng polyp }\end{array}$} & \multicolumn{2}{|c|}{$10-19$} & \multicolumn{2}{|c|}{$20-29$} & \multicolumn{2}{|c|}{$\geq \mathbf{3 0}$} & \multicolumn{2}{|c|}{ Tông } \\
\hline & $\mathbf{n}$ & $\%$ & $\mathbf{n}$ & $\%$ & $\mathbf{n}$ & $\%$ & $\mathbf{n}$ & $\%$ \\
\hline Không cuống & 3 & 75 & 2 & 50 & 3 & 60 & 8 & 61,5 \\
\hline Có cuống & 1 & 25 & 1 & 25 & 1 & 20 & 3 & 23,1 \\
\hline Nửa cuống & 0 & 0 & 0 & 0 & 1 & 20 & 1 & 7,7 \\
\hline Dạng phắng & 0 & 0 & 1 & 25 & 0 & 0 & 1 & 7,7 \\
\hline Tống & 4 & 100 & 4 & 100 & 5 & 100 & 13 & 100 \\
\hline $\mathrm{p}$ & & & & & & & & \\
\hline
\end{tabular}

Nhận xét: Polyp ung thư không cuống có tỷ lệ cao nhất $61,5 \%$.

3.8 Đặc điểm bề mặt polyp ung thư trên hình ảnh nội soi

Bảng 7: Đăc điểm bề măt polyp ung thư theo kích thước

\begin{tabular}{|c|c|c|c|c|c|c|c|c|}
\hline \multirow{2}{*}{$\begin{array}{l}\text { Kích thước }(\mathrm{mm}) \\
\text { Bề mặt polyp }\end{array}$} & \multicolumn{2}{|c|}{$10-19$} & \multicolumn{2}{|c|}{$20-29$} & \multicolumn{2}{|c|}{$\geq \mathbf{3 0}$} & \multicolumn{2}{|c|}{ Tống } \\
\hline & $\mathbf{n}$ & $\%$ & $\mathbf{n}$ & $\%$ & $\mathbf{n}$ & $\%$ & $\mathbf{n}$ & $\%$ \\
\hline Sần sùi & 2 & 50 & 2 & 50 & 4 & 80 & 8 & 61,5 \\
\hline Loét & 1 & 25 & 2 & 50 & 1 & 20 & 4 & 30,8 \\
\hline Xung huyết & 1 & 25 & 0 & 0 & 0 & 0 & 1 & 7,7 \\
\hline Nhăn & 0 & 0 & 0 & 0 & 0 & 0 & 0 & 0 \\
\hline Tống & 4 & 100 & 4 & 100 & 5 & 100 & 13 & 100 \\
\hline $\mathrm{p}$ & & & & & 05 & & & \\
\hline
\end{tabular}

Nhận xét: Polyp có bề mặt sần sùi chiếm $61,5 \%$, loét $30,8 \%$, polyp mặt nhẵn không có polyp nào bị ung thư.

\section{BÀN LUÂ̂N}

- Về tuối của bệnh nhân bị polyp ung thư: Trong nghiên cứu của chúng tôi tuổi thấp nhất bị polyp ung thư là 32 tuổi, tuổi từ 40 trở lên chiếm $92,3 \%$.Kết quả này cũng tương tự kết quả nghiên cứu của Quách Trọng Đức [4] là những người polyp đại trực tràng trên 40 tuổi chiếm
91\%. Tuy nhiên,theo Hiệp Hội Ung thư Hoa kỳ năm 2018 (the American Cancer Society (ACS))[5] khuyến cáo những bệnh nhân trên 45 tuổi nên tầm soát ung thư đại trực tràng vì phần lớn những ung thư đại trực tràng gặp ở người từ 45 tuổi trở lên. Trong nghiên cứu của chúng tôi có 1 bệnh nhân 32 tuổi có polyp ung thư kích 
thước $4,5 \mathrm{~cm}$, đây cũng là trường hợp bệnh nhân trẻ bị polyp ung thư, điều đó cũng có nghĩa rằng polyp có kích thước lớn có thể bị ung thư kể cả ở người trẻ tuổi.

Nghiên cứu của chúng tôi ghi nhận đại tràng sigma và trực tràng là 2 vị trí gặp nhiêu polyp ung thư nhất với tỷ lệ $46,2 \%$ và $38,5 \%$. Điều này cho thấy polyp ung thư thường gặp ở đại tràng sigma và trực tràng $(84,7 \%)$ nhiêu hơn vị trí khác, kết quả này cũng tương tự kết quả nghiên cứu của Quách Trọng Đức [4], với tỷ lệ ung thư đai tràng sigma - trực tràng $95 \%$.

Về mặt đại thể trên nội soi, kết quả nghiên cứu của chúng tôi cho thẩy tổn thương sần sùi, loét chiếm tỷ lệ $61,5 \%$ và $30,8 \%$ (tổng $92,3 \%$ ), kết quả này cũng tương tự nghiên cứu của Quách Trọng Đức [4], tổn thương sùi loét chiếm $90 \%$ các loại tổn thương.

\section{KẾT LUÂ̂N}

Polyp đai trực tràng được xem là tổn thương tiền ung thư, bệnh nhân $\geq 40$ tuổi nên nội soi đại trực tràng tầm soát ung thư, nếu có polyp đặc biệt polyp $\geq 10 \mathrm{~mm}$ nên cắt. Polyp có bề mặt loét hoặc sần sùi chiếm tỷ lệ $92,3 \%$.

\section{TÀI LIÊUU THAM KHẢO}

1. Shussman N, Wexner SD. Colorectal polyps and polyposis syndromes. Gastroenterol Rep. 2014;2(1):1-15.

2. Øines M, Helsingen LM, Bretthauer M, Emilsson L. Epidemiology and risk factors of colorectal polyps. Best Pract Res Clin Gastroenterol. 2017;31(4):419-424.

3. Nguyễn Thúy $\mathbf{V}$. Tỉ lệ bệnh lý đại tràng của bệnh nhân Bệnh viện Hữu Nghị qua 6157 ca soi đại tràng. Khoa Học Tiêu Hóa Việt Nam. 2012;7(26):1735-1741.

4. Quách Trọng $\boxplus$, Nguyễn Trường $K$. Đặc điểm nội soi và mô bệnh học của ung thư đại trực tràng: nghiên cứu loạt ca trên 1033 trường hợp. Học Thành Phố Hồ Chí Minh. 2015;19(1):114-118.

5. Wolf AMD, Fontham ETH, Church TR, et al. Colorectal cancer screening for average-risk adults: 2018 guideline update from the American Cancer Society. CA Cancer J Clin. 2018;68(4):250-281.

\section{ĐĂC ĐIỂM LÂM SÀNG, CÂN LÂM SÀNG CỦA HộI CHỨNG NGỪNG THỞ' TẮC NGHẼN KHI NGỦ Ở BÊ̂NH NHÂN TRÊN 65 TUỔI}

\section{TÓM TẮT}

Mục tiêu: Mô tả đặc điểm lâm sàng, cận lâm sàng của hổi chứng ngững thở tắc nghẽn khi ngủ ở bệnh nhân trên 65 tuổi tại Bệnh viện Bạch Mai. Đối tượng và phương pháp: Nghiên cứu mô tả cắt ngang trên 65 tuổi chẩn đoán mắc hội chứng ngừng thở tắc nghẽn khi ngủ được điều trị tại Bệnh viện Bạch Mai từ năm 9/2020 đến năm 7/2021. Kết quả. Triệu chứng ban đêm gặp nhiều nhất là ngáy to khi ngủ chiếm $92.5 \%$ và thức giấc nhiều lần trong đêm chiếm $75 \%$. Có tới $97.6 \%$ số bệnh nhân có Mallampati độ 3-4 $(n=42)$. Chỉ số ngưng giảm thở trung bình cả hai giới là $32.63(n=45)$, trong đó $73.3 \%$ số bệnh nhân có AHI từ trung bình - nặng. Bệnh nhân mắc hội chứng ngừng thở khi ngủ tắc nghẽn có có điểm Epworth > 10 và triệu chứng đau đâu buổi sáng chỉ chiếm tỉ lệ $20 \%$ trong tổng số 40 bệnh nhân. Kết luận: Đổi tượng người > 65 tuổi mắc OSA có biểu hiển buồn ngủ ngày, hay đau đâu, khó chịu vào buổi sáng thấp. Ngủ ngáy là triệu chứng ban đêm gặp nhiều nhất ở

\footnotetext{
${ }^{1}$ Đại học Y Hà Nôi

${ }^{2}$ Bệnh viện Đa khoa Tâm Anh

Chịu trách nhiệm chính: Ngô Quý Châu

Email: chaunq@tamanhhospital.vn

Ngày nhận bài: 4.8.2021

Ngày phản biên khoa học: 30.9.2021

Ngày duyệt băi: 6.10 .2021
}

\section{Lê Thị Hồng Thắm ${ }^{1,2}$, Ngô Quý Châu ${ }^{1,2}$}

bệnh nhân trên 65 tuổi có ngừng thở tắc nghẽn với chỉ sổ $A H I$ từ trung bình đền nặng. Do vậy, cân đặc biệt khuyến cáo đối với những người có biểu hiện ngủ ngáy nhằm phát hiện sớm hội chứng ngừng thở khi ngủ do tắc nghẽn và điều trị kịp thời cho người bênh

Tư khoá: hội chứng ngừng thở khi ngủ, tắc nghẽn.

\section{SUMMARY}

THE CHARACTERISTICS OF OBSTRUCTIVE SLEEP APNEA SYNDROME IN PATIENTS AGED

Objective: To determine the physical exam and diagnostic testing in patients who suffer from obstructive sleep apnea syndrome aged over 65 years old in Bach mai Hospital. Methods: Forty-five patients who suffer from obstructive sleep apnea syndrome aged more than 65 years old agreed to participate in our study and performed polysomnography, from $9 / 2020$ to $7 / 2021$. Results. The most common nocturnal symptom is loud snoring when sleeping, reach to $92.5 \%$, and waking up many times during the night, reach to $75 \%$. $97.6 \%$ of patients had Mallampati grade 3-4 $(n=42)$ with an average apnea index of both sexes of $32.63(n=45)$. Of which $73.3 \%$ of patients have moderate to severe AHI. Patients with obstructive sleep apnea syndrome have Epworth score $>10$ and morning headache symptoms only accounted for $20 \%(n=40)$. Conclusion: Subjects over 65 years of age with OSA presented with daytime drowsiness, headache, and low morning irritability. 